\title{
Dual-Polarized Indoor Antenna for Digital TV Reception
}

\author{
Guilherme B. dos Santos \\ Cristiano Akamine \\ Edson T. C. dos Santos
}




\title{
Dual-Polarized Indoor Antenna for Digital TV Reception
}

\author{
Guilherme B. dos Santos, Cristiano Akamine, and Edson T. C. dos Santos
}

\begin{abstract}
This paper presents the design and simulations of a dual-polarized indoor antenna to receive the signal provided by the traditional ISDB-T system, operating in Ultra-High Frequency range destined to the radio-frequency channels after analog switch-off. The design goals were towards low cost, simple construction and implementation computational for indoor applications and with good performance in terms return loss within the frequency band. The antenna was designed and optimized using a full wave electromagnetic solver, and the results indicated that the proposed antenna has a good performance, simple structure and is a suitable candidate to be employed in the current digital television standard as in the nextgeneration of digital broadcasting.
\end{abstract}

Index Terms-dual-polarized antenna, indoor antenna, integrated services digital broadcasting terrestrial (ISDB-T), MWS-CST Studio.

\section{INTRODUCTION}

$\mathrm{W}$ ith the establishment of the digital television system, improvements emerged compared to the analog television system, such as bringing users better quality picture, audio and video. This transition of the analog/digital system is already a reality in Brazil so that organs linked to the Brazilian government are performing the process of Analog Switch-Off (ASO). The ASO aims to release the electromagnetic spectrum in the Ultra-High Frequency (UHF) band to allow the expansion of mobile broadband. Due to this operation in adjacent bands, there is a possibility that the Long-Term Evolution (LTE) signal interferes Digital Terrestrial Television Broadcasting (DTTB).

As the LTE uplink and downlink operating range use the same channels used for television, 52 to 69 , the saturation of the tuner or the image frequency can degrade the reception of DTTB signal [1]. This means an interruption in receiving programming, frozen images or black screen. In critical cases, to preserve the quality of DTTB signal reception is required a combination of several mitigation measures. The filter installation on LTE transmitters is intended to reduce interfering emissions as much as possible. Furthermore, the installation of filters on DTTB receivers aims to increase their protection against degradation [2]. However, the resources needed to minimize the impact on the viewer are not limited to the development and manufacture of filters, but also in new changes in the configuration of the antennas.

The new DTTB requires a high spectrum efficiency since Ultra High Definition Television (UHDTV) transmission is necessary and part of the spectrum are used to wireless

This work was supported in part by the Coordination for the Improvement of Higher Education Personnel (CAPES), National Research and Educational Network (RNP), National Counsel of Technological and Scientific Development (CNPq) and MackPesquisa.

This open access article is distributed under a Creative Commons Attribution (CC-BY) license http://www.set.org.br/ijbe/ doi: 10.18580/setijbe.2017.6 Web Link: http://dx.doi.org/10.18580/setiibe.2017.6 


\section{FUNDAMENTAL PARAMETERS OF ANTENNAS}

\section{A. Definition of the term antenna}

IEEE Standard Definitions of Terms for Antennas defines antenna as an element that radiates and receives radio waves. However, [8] describes an antenna as a transitional structure between the free space and the transmission line. In other words, an antenna is a device that converts electromagnetic energy guided by the transmission line into radiated electromagnetic energy in the free space.

\section{B. Radiation pattern}

The radiation pattern of an antenna is the graphical representations of its radiation and power properties as a function of the angle at a fixed distance [8]. The electric and magnetic fields are some types of diagrams. In the case of dual-polarized antennas, it is interesting to present an omnidirectional irradiation pattern, Fig. 1 [8], as reported [4].

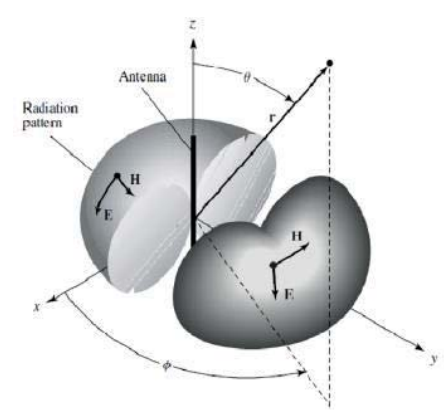

Fig. 1. Omnidirectional Irradiation Pattern.

\section{Return loss}

Return loss represents the quantities of power reflected from the antenna. This parameter can be obtained using Equation 1, where $\Gamma(\omega)$ is the reflection coefficient [8].

$$
S_{11}=20 \log (|\Gamma(\omega)|)
$$

\section{Bandwidth}

Bandwidth is the antenna operating range, where performance meets specific standards such as gain, directivity, impedance, among others [8]. The good performance of the antenna is within the frequency range close to the center frequency, which makes it necessary for the frequency variations of the upper and lower frequencies to be acceptable. The bandwidth is calculated using the Equation 2.

$$
B W=f_{\text {upper }}-f_{\text {lower }}
$$

\section{E. Fractional bandwidth}

The fractional bandwidth of an antenna is a measure of how wideband the antenna is. This parameter is calculated by Equation 3.

$$
F B W=\frac{B W}{f_{\text {central }}}
$$

\section{F. Polarization}

Per [9], the signal polarization can be defined regarding a signal transmitted or received by an antenna in one direction. The antenna polarization radiated a signal considered as the trajectory described by the electric field vector when viewed by an observer who sees the wave moving away from itself. The total electric field of this radiated wave is composed of orthogonal components that differ in amplitudes $\left(E_{x o}\right.$ and $\left.E_{y o}\right)$ and phases $\left(\phi_{x}\right.$ and $\left.\phi_{y}\right)$, Equations 4 and 5, where through the orientation it is possible to determine the type of polarization that the antenna radiates. The total electric field of this plane wave propagating in the $\mathrm{z}$ direction can be represented by Equation 6.

$$
\begin{gathered}
E_{x}(z, t)=E_{x o} \cdot \cos \left(\omega t+\beta z+\phi_{x}\right) \\
E_{y}(z, t)=E_{y o} \cdot \cos \left(\omega t+\beta z+\phi_{y}\right) \\
E(z, t)=E_{x}(z, t)+E_{y}(z, t)
\end{gathered}
$$

In general, most antennas radiate either linear or circular polarization. A linear polarized antenna radiates wholly in one plane containing the direction of propagation. In a circular polarized antenna, the plane of polarization rotates in a circle making one complete revolution during one period of the wave. An antenna is said to be vertically polarized (linear) when its electric field is perpendicular to the Earth's surface and horizontally polarized (linear) when their electric field is parallel to the face of the earth. A circular polarized wave radiates energy in both the horizontal and vertical planes and all planes in between. The difference, if any, between the maximum and the minimum peaks as the antenna, is rotated through all angles, is called the axial ratio and is usually specified in decibels $(\mathrm{dB})$. If the axial ratio is near $0 \mathrm{~dB}$, the antenna is said to be circular polarized. The polarization is linear if the axial ratio is greater than $3 \mathrm{~dB}[10]$.

\section{Development Antenna Design with Single- POLARIZATION}

With the availability of software for modeling and simulation of antennas, it is possible to predict the resulting characteristics very close to the confection of a real antenna. The software chosen to perform all the simulations was the MWS-CST Studio version 2014 [11].

The simulations served to identify which model of antenna presented the bandwidth closest to the intended, to select the most viable for the final confection model.

All metal structures are perfect electrical conductors (PEC), the ground plane is a thin sheet (thickness $0.035 \mathrm{~mm}$ ), the feeding was performed with an impedance $50 \Omega$ and range of interest $S_{11} \leq-10 \mathrm{~dB}$.

\section{A. Quarter-wavelength filament monopole structure}

The project started from a monopole antenna consisting of a cylindrical filamentary radiating element supported by a ground plane. The calculation of the antenna height was made to meet the center frequency. This value is the averaging DTV 
frequency range $470 \mathrm{MHz}$ to $698 \mathrm{MHz}$. By calculating the average of this frequency range, the center frequency value was found to be $584 \mathrm{MHz}$, and it was possible to calculate the antenna height using Equation 7. Where $\lambda_{m}$ is the average wavelength, and $v$ is the speed of light.

$$
\lambda_{m}=\frac{v}{f_{\text {central }}}
$$

The obtained value of the average wavelength was equal to $513.7 \mathrm{~mm}$. A quarter-wavelength structure is the characteristic of the monopole antenna. The final metric dimension was assumed with a height of $\mathrm{H}=130 \mathrm{~mm}$ and a ground plane with length $500 \times 500 \mathrm{~mm}$. After performing some simulations, it was observed limitations in bandwidth this structure, $\mathrm{BW}=0.11781 \mathrm{GHz}$. A cylindrical monopole replaced this structure and verified its influence on bandwidth.

\section{B. Quarter-wavelength cylindrical monopole structure}

The filament antenna was superseded by a cylindrical antenna to increase bandwidth. Per [8], as the cylinder radius increases, the bandwidth also tends to grow. Simulations were performed, where the radius of the cylindrical antenna and the length of the ground plane were varied, and an increase of bandwidth was observed, resulting in $\mathrm{BW}=0.14573 \mathrm{GHz}$, Fig. 2, using radius $=4 \mathrm{~mm}$ and the ground plane of $500 \times 500$ mm, Fig. 3.

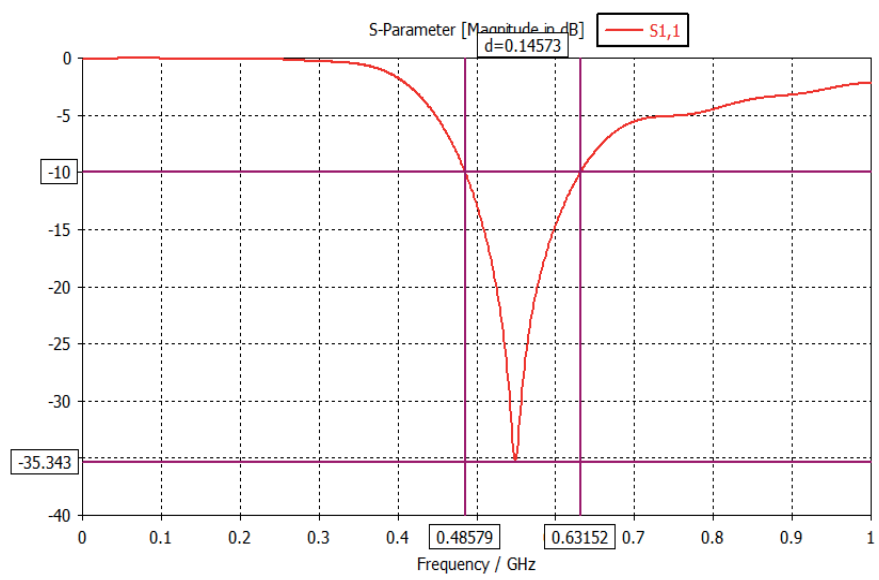

Fig. 2. Bandwidth obtained $\mathrm{BW}=0.14573 \mathrm{GHz}$ of the cylindrical monopole antenna.

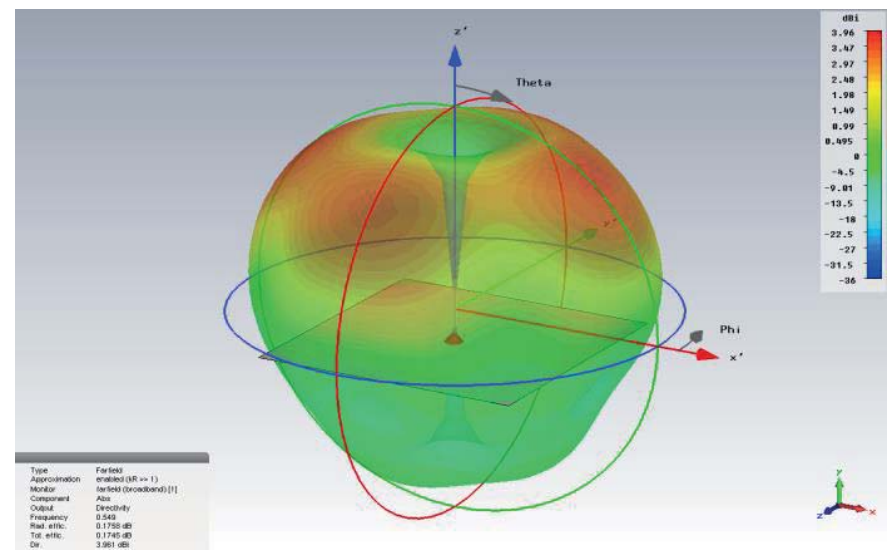

Fig. 3. Tridimensional radiation pattern of the cylindrical monopole antenna.
It has been observed that at first, the cylindrical antenna cannot satisfactorily cover the entire band, as well as the filamentary form. Although it has excellent omnidirectional characteristics, what is desirable, new structures must be sought to meet both bandwidth and omnidirectionality.

\section{Planar monopole structure}

The planar monopole antenna is an antenna model that has been extensively studied in the literature. According to [12], this type of antenna can cover a bandwidth of the order of $1: 18$, also serve as a reference for antenna designs that operate in the $\mathrm{S}, \mathrm{X}$ and $\mathrm{C}$ bands. In most cases, this structure is formed by a square radiating element supported by a ground plane and fed by an SMA connector. Fig. 4 [13], where W is the width and $\mathrm{L}$ is the length of the square radiating element, and the $\mathrm{h}$ is the distance between the ground plane and the radiating element, called gap.

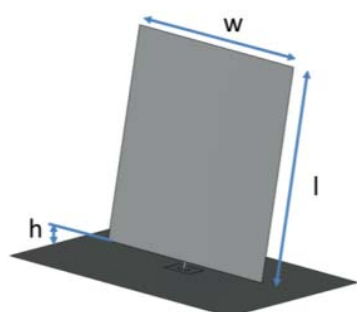

Fig. 4. Planar monopole antenna over a ground plane and its geometric parameters.

With the results of the simulations, it was observed that the gap distance substantially influences the bandwidth and operating point of the center frequency. Thus, the value of the optimal gap is between the null value and $1 \mathrm{~mm}$ of distance. Larger gap distances strongly deviate the center frequency and the beginning of the resonant frequency. The results of the simulations indicated the value of gap $=1 \mathrm{~mm}$, which is closer to 1 of the Smith Chart, that is, matched with the feed impedance of $50 \Omega$. The $\mathrm{W}, \mathrm{L}$, and ground plane dimensions were also varied and analyzed through the Smith Chart, and the results of the simulations indicated $\mathrm{W}=80 \mathrm{~mm}, \mathrm{~L}=150$ $\mathrm{mm}$ and ground plane $200 \times 200 \mathrm{~mm}$, Fig. 6, as the combination that resulted in a bandwidth close to the desired, Fig 5.

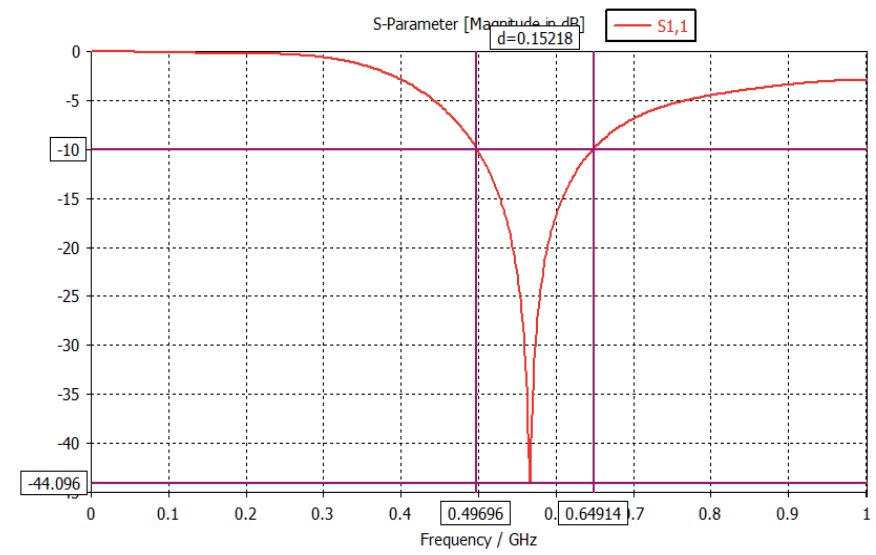

Fig. 5. Bandwidth obtained $\mathrm{BW}=0.15218 \mathrm{GHz}$ of the planar monopole antenna. 


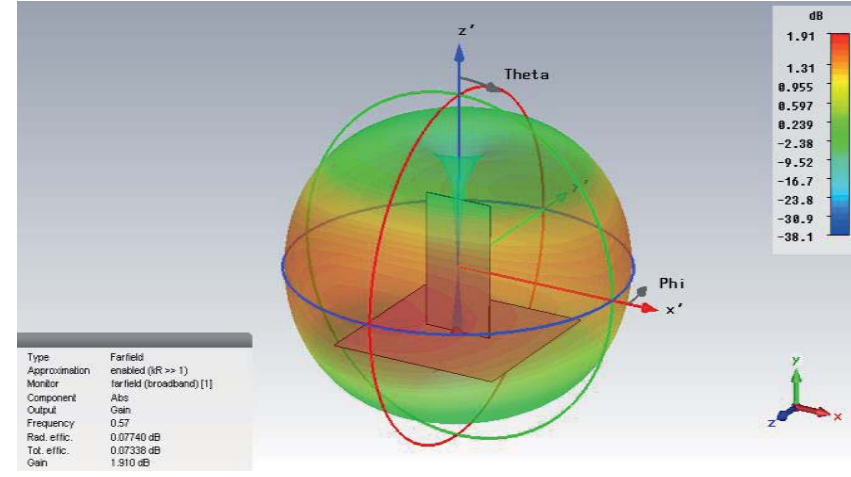

Fig. 6. Tridimensional radiation pattern of the planar monopole antenna.

\section{Planar monopole structure with parasitic elements}

Among the three structures designed and simulated, the planar monopole antenna was the structure that presented the best response, in the band criterion, and in the guarantee of omnidirectionality. Table I indicates that the planar monopole antenna still has a fractional band higher than the others simulated.

TABLE I

PERFORMANCE COMPARISON OF PROJECTED STRUCTURES (FREQUENCIES IN GHz)

\begin{tabular}{cccccc}
\hline \hline Structures & $f_{\text {lower }}$ & $f_{\text {central }}$ & $f_{\text {upper }}$ & $B W$ & $F B W(\%)$ \\
\hline Filament & 0.492 & 0.543 & 0.610 & 0.118 & 21.7 \\
\hline Cylindrical & 0.485 & 0.549 & 0.631 & 0.146 & 26.6 \\
\hline Planar & 0.496 & 0.564 & 0.649 & 0.153 & 27.1 \\
\hline \hline
\end{tabular}

However, the planar monopole antenna in this configuration also cannot cover all the desired bandwidth. For this reason, it was necessary to redeem in the literature some techniques that could increase the bandwidth of an antenna. Among the most used are: resistive load, alteration in structure and addition of parasitic elements and elements of matching or structures of matching [14]. The technique chosen for this project was to the addition of parasitic elements in the structure.

It was first inserted into the planar monopole structure a single rectangular parasitic element and verified its influence on the bandwidth. Similarly, to the previous simulations, the metric dimensions of the parasite element, as well as its distance to the rectangular radiating element, were varied and analyzed by Smith Chart. After successive simulations, the results indicated that with a single parasitic element attached to the structure it was possible to increase the bandwidth around $0.023 \mathrm{GHz}$, leading to a total bandwidth of $0.181 \mathrm{GHz}$.

A second identical rectangular parasitic element, Fig. 7, was attached to the structure and through the simulations, an increase of band was verified compared to the structure with a single parasitic element. With the parasitic elements designed in the dimensions $\mathrm{W}=110 \mathrm{~mm}, \mathrm{~L}=100 \mathrm{~mm}$ and its distance to the rectangular radiating element $=55 \mathrm{~mm}$, was possible to increase the bandwidth around $0.069 \mathrm{GHz}$, resulting in a total bandwidth of $0.250 \mathrm{GHz}$, Fig. 8. Fig. 9 shows the tridimensional radiation pattern this new structure.

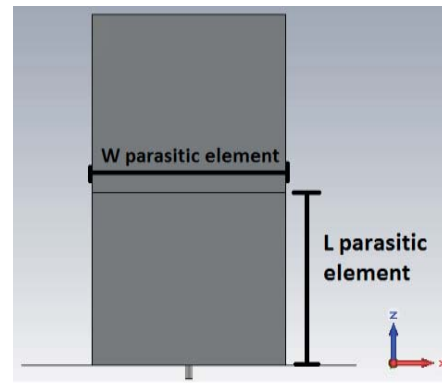

(a)

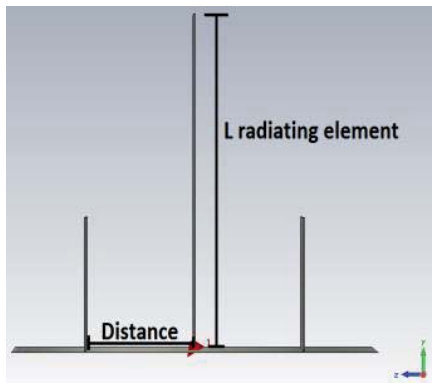

(b)
Fig. 7. Planar monopole structure with two parasitic elements (a) its geometric parameters, (b) distance to the rectangular radiating element.

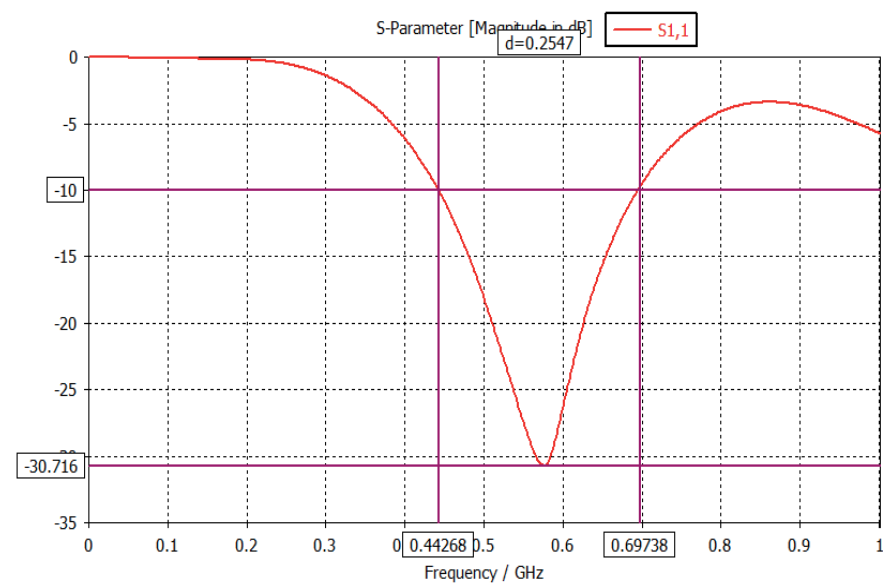

Fig. 8. Bandwidth obtained $\mathrm{BW}=0.25470 \mathrm{GHz}$ of the planar monopole structure with two parasitic elements.

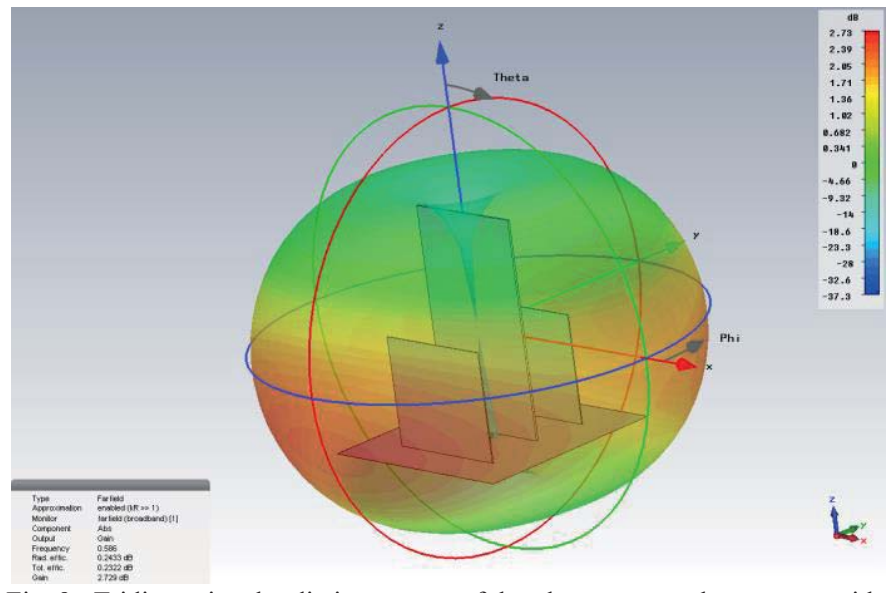

Fig. 9. Tridimensional radiation pattern of the planar monopole structure with two parasitic elements.

Table II compares the performance of the simulated anterior structures with the planar monopole antenna with parasitic elements. Comparing the performances was verified that the planar monopole antenna with two parasitic elements exceeded in all the criteria previously discussed. The structure presented the highest bandwidth and percentage of a fractional band, besides to satisfying optimal values of lower, central and upper frequency. Given the reasons offered, this structure 
proved to be the most feasible for the confection of the dualpolarized antenna that is presented in the Section IV.

TABLE II

PERFORMANCE COMPARISON OF THE PREVIOUS STRUCTURES SIMULATED WITH THE PLANAR MONOPOLE ANTENNA WITH PARASITIC ELEMENTS (FREQUENCIES IN GHz)

\begin{tabular}{cccccc}
\hline \hline Structures & $f_{\text {lower }}$ & $f_{\text {central }}$ & $f_{\text {upper }}$ & BW & FBW (\%) \\
\hline Filament & 0.492 & 0.543 & 0.610 & 0.118 & 21.7 \\
\hline Cylindrical & 0.485 & 0.549 & 0.631 & 0.146 & 26.6 \\
\hline Planar & 0.496 & 0.564 & 0.649 & 0.153 & 27.1 \\
\hline $\begin{array}{c}\text { Planar (single } \\
\text { parasitic } \\
\text { element) }\end{array}$ & 0.511 & 0.588 & 0.693 & 0.181 & 30.7 \\
\hline $\begin{array}{c}\text { Planar (two } \\
\text { parasitic } \\
\text { elements) }\end{array}$ & 0.442 & 0.586 & 0.697 & 0.255 & 43.5 \\
\hline \hline
\end{tabular}

\section{Dual-Polarized AnTEnNa Design}

Based on the analysis of the single-polarized antenna in the previous section, it was verified that the planar monopole antenna with two parasite elements was the structure that presented the best results and for this reason was the structure chosen for the modeling of the dual-polarized antenna.

According [5] dual-polarized antennas are antennas that have the characteristic of radiating dual orthogonal linear polarization from the same structure, Fig. 10 [15], where each polarization is lagged at an angle of 90 degrees to another.

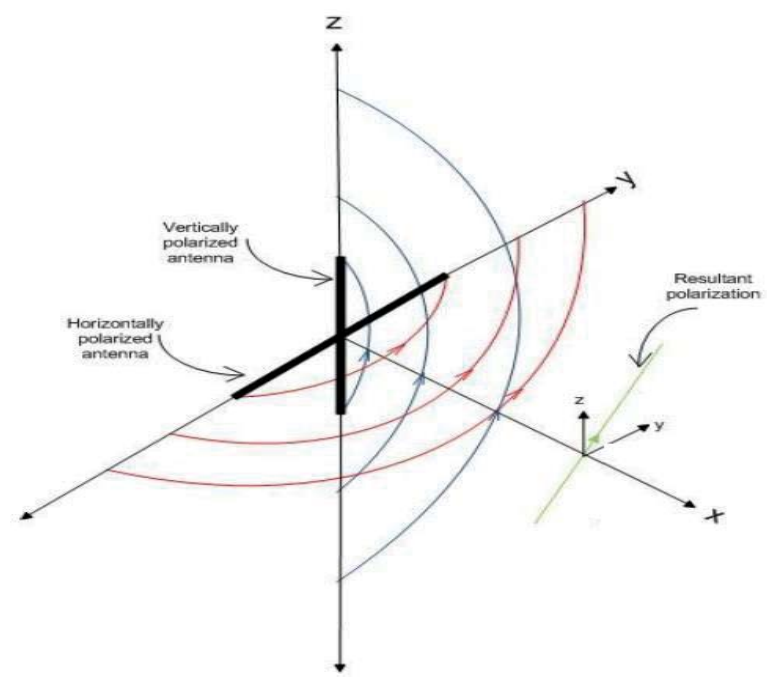

Fig. 10. Orthogonal linear polarizations of a dual-polarized antenna.

The planar monopole structure with two parasitic elements has a vertical radiating element supported by a ground plane, characterizing a vertical polarization. As a way of obtaining the horizontal polarization, a second planar monopole structure was attached chosen the structure. The main radiating element of the second structure was placed in an orthogonal position to the radiating element of the selected structure. Thus, when one of the ports is activated, and the other is matched with the feed impedance of $50 \Omega$, one polarization is obtained. The other polarization, orthogonal to the first, occurs when the situation is the reverse: the second port is active, and the other port is matched. The basic design of proposed dual-polarized antenna is shown in Fig. 11.

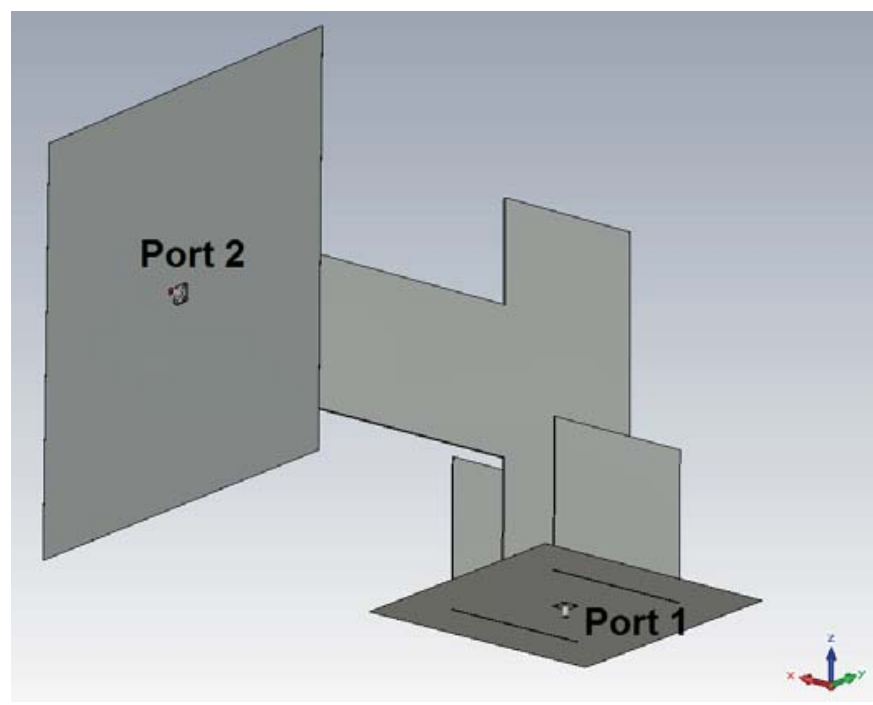

(a)

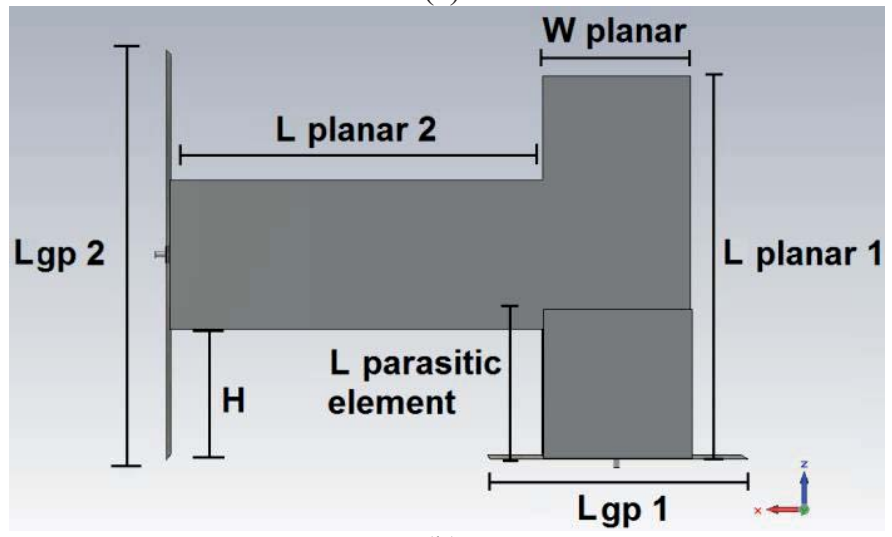

(b)

Fig. 11. Dual-polarized antenna proposed (a) view of the ports, (b) its geometric parameters.

\section{Simulation AND Results}

The dimensions of the proposed antenna after optimization are follows: $\mathrm{L}$ planar $1=280 \mathrm{~mm}, \mathrm{~L}$ planar $2=170 \mathrm{~mm}, \mathrm{~L}$ parasitic element $=110 \mathrm{~mm}, \mathrm{~W}$ planar $=110 \mathrm{~mm}, \operatorname{Lgp} 1=190$ x $190 \mathrm{~mm}, \operatorname{Lgp} 2=300 \times 300 \mathrm{~mm}, \mathrm{H}=100 \mathrm{~mm}$ and the distances of the parasitic elements to the radiating element were maintained in $55 \mathrm{~mm}$. Fig. 12 shows return loss curves of both port $1\left(S_{11}\right)$ and port $2\left(S_{22}\right)$. At the operating frequency, both ports have return loss values lower than $-10 \mathrm{~dB}$. The isolation between two ports is higher which varies between 11 to $20 \mathrm{~dB}$ in operating band. The results show that the proposed antenna obtains enough bandwidth at port 1, but the bandwidth at port 2 is inferior to port 1 to ensure the high isolation performance. 


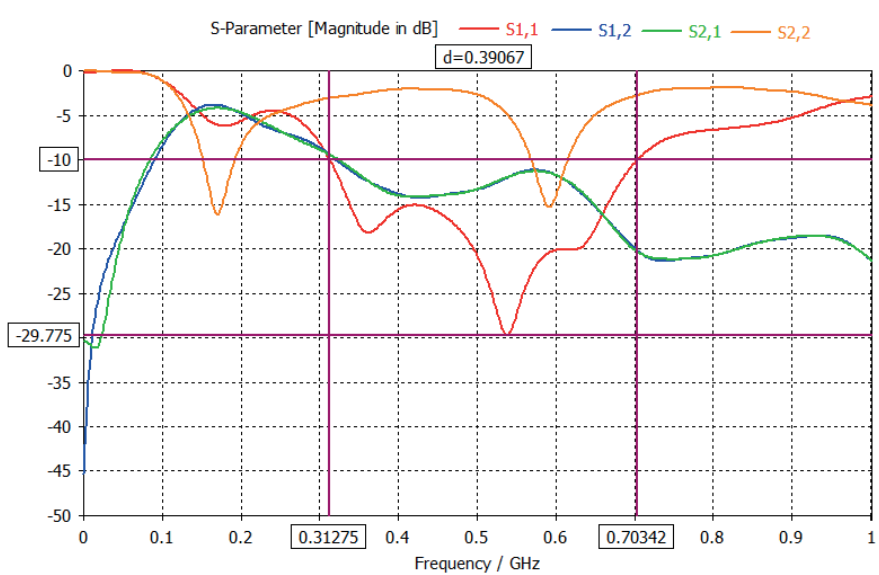

Fig. 12. Return loss of the dual-polarized antenna, $S_{11}$ (port 1) and $S_{22}$ (port 2).

Fig. 13 shows the axial ratio of the port 1 and the port 2 . Through the axial ratio curves, a minimum peak of $11 \mathrm{~dB}$ was observed for port 1 and a minimum peak of $9 \mathrm{~dB}$ for port 2 . Both ports obtained minimum peak values much higher than 3 $\mathrm{dB}$, that is, both planar monopole structures can be referred to as linear polarizations.

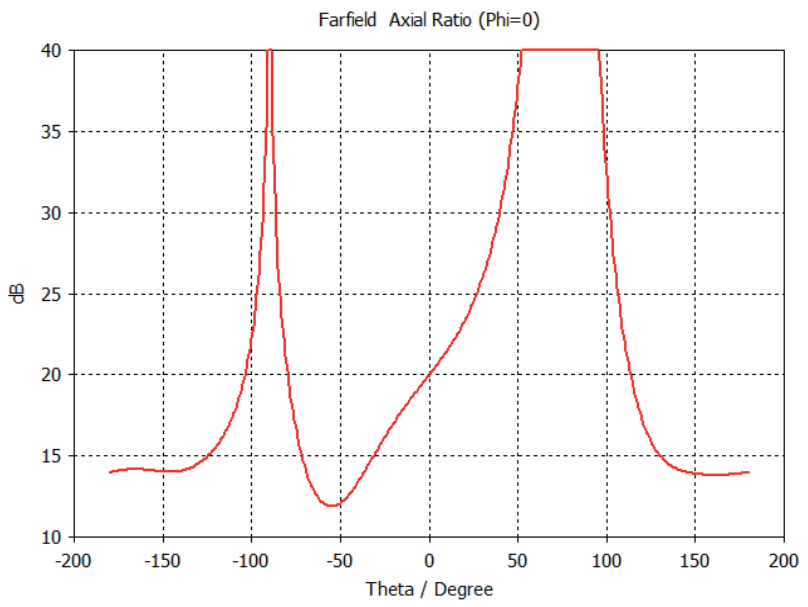

(a)

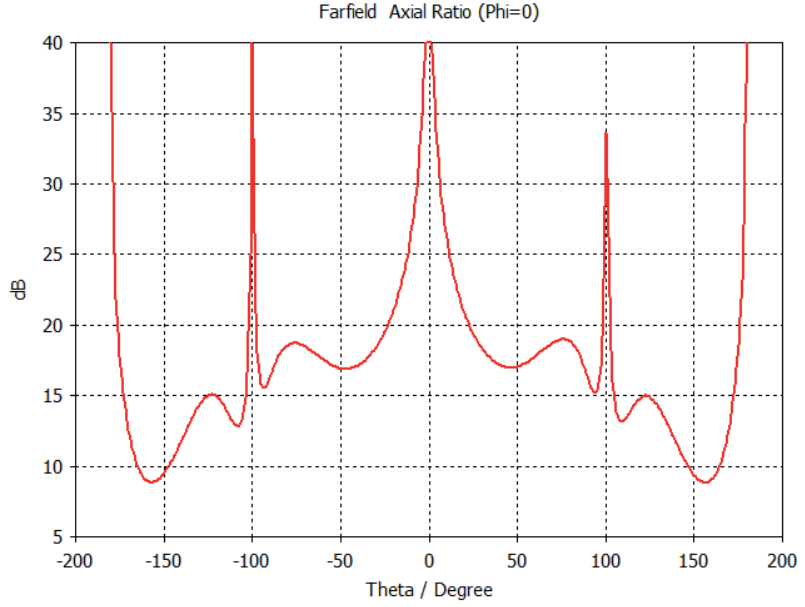

(b)

Fig. 13. Axial ratio curves (a) port 1, (b) port 2 .

When the direction is not stated, the polarization is taken to be the polarization in the direction of maximum gain. There are several choices of the axis. From these, spherical and Ludwig 3 coordinates seem more relevant. To see polarization gains Ludwig 3 coordinate system is better [15]. Fig. 14 compares the Ludwig 3 [16] gain values in linear polarization. It was observed that the vertical gain value is higher than the horizontal gain value in port 1 . Therefore, it can be concluded that this structure radiates a polarization in vertical mode. In port 2, the horizontal gain value is greater than the vertical gain value, so we can conclude that this antenna irradiates a polarization in the horizontal mode.

\begin{tabular}{|c|c|c|c|}
\hline $\begin{array}{l}\text { Type } \\
\text { Approximation } \\
\text { Monitor }\end{array}$ & $\begin{array}{l}\text { Far field } \\
\text { enabled (kR } \gg 1 \text { ) } \\
\text { far field (broadband) [1] }\end{array}$ & $\begin{array}{l}\text { Type } \\
\text { Approximation } \\
\text { Monitor }\end{array}$ & $\begin{array}{l}\text { Far field } \\
\text { enabled (kR } \gg 1 \text { ) } \\
\text { far field (broadband) [1] }\end{array}$ \\
\hline Component & Ludwig 3 Horizontal & Component & Ludwig 3 Vertical \\
\hline $\begin{array}{l}\text { Output } \\
\text { Frequency }\end{array}$ & $\begin{array}{l}\text { Gain } \\
0.584\end{array}$ & $\begin{array}{l}\text { Output } \\
\text { Frequency }\end{array}$ & $\begin{array}{l}\text { Gain } \\
0.584\end{array}$ \\
\hline Rad. effic. & $0.2474 \mathrm{~dB}$ & Rad effic. & $0.2474 \mathrm{~dB}$ \\
\hline Tot. effic. & $-0.1199 \mathrm{~dB}$ & Tot. effic. & $-0.1199 \mathrm{~dB}$ \\
\hline Gain(Abs) & $4.924 \mathrm{~dB}$ & Gain(Abs) & $4.924 \mathrm{~dB}$ \\
\hline Gain(Horizo.) & $4.529 \mathrm{~dB}$ & Gain(Vertic.) & $4.776 \mathrm{~dB}$ \\
\hline
\end{tabular}

(a)

\begin{tabular}{|c|c|c|c|}
\hline $\begin{array}{l}\text { Type } \\
\text { Approximation } \\
\text { Monitor }\end{array}$ & $\begin{array}{l}\text { Farfield } \\
\text { enabled (kR } \gg 1 \text { ) } \\
\text { far field (broadband) [2] }\end{array}$ & $\begin{array}{l}\text { Type } \\
\text { Approximation } \\
\text { Monitor }\end{array}$ & $\begin{array}{l}\text { Far field } \\
\text { enabled (kR } \gg 1 \text { ) } \\
\text { far field (broadband) [2] }\end{array}$ \\
\hline Component & Ludwig 3 Horizontal & Component & Ludwig 3 Vertical \\
\hline Output & Gain & Output & Gain \\
\hline Frequency & 0.584 & Frequency & 0.584 \\
\hline Rad. effic. & $-0.3368 \mathrm{~dB}$ & Rad. effic. & $-0.3368 \mathrm{~dB}$ \\
\hline Tot. effic. & $-0.8607 \mathrm{~dB}$ & Tot. effic. & $-0.8607 \mathrm{~dB}$ \\
\hline Gain(Abs) & $4.080 \mathrm{~dB}$ & Gain(Abs) & $4.080 \mathrm{~dB}$ \\
\hline Gain(Horizo.) & $4.076 \mathrm{~dB}$ & Gain(Vertic.) & $2.896 \mathrm{~dB}$ \\
\hline
\end{tabular}

b)

Fig. 14. Ludwig 3 gain comparison in linear polarization (a) port 1, (b) port 2.

The horizontal and vertical polarization components can be matched to the co and cross-polarization. Co-polarization it as the polarization that an antenna is desired to radiate and crosspolarization is the polarization orthogonal to co-polarization [15]. From Fig. 14, it can be understood that port 1 has low Ludwig 3 in horizontal gain and higher Ludwig 3 in vertical gain. Therefore, for this port, a horizontal gain is the crosspolarization gain, and vertical gain is the co-polarization gain. The opposite is seen on port 2, where Ludwig 3 horizontal is the co-polarization gain and the Ludwig 3 vertical is the crosspolarization gain. Fig. 15 presents the co and crosspolarization radiation patterns in $\mathrm{E}$ and $\mathrm{H}$ planes.

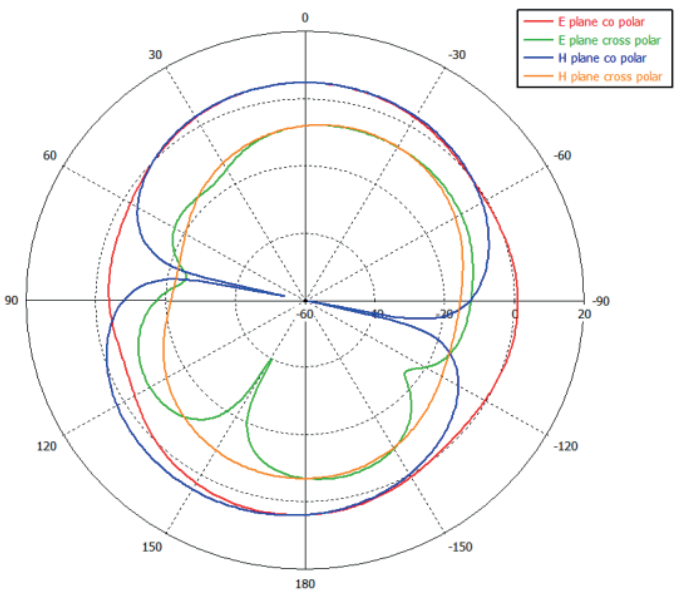

(a) 


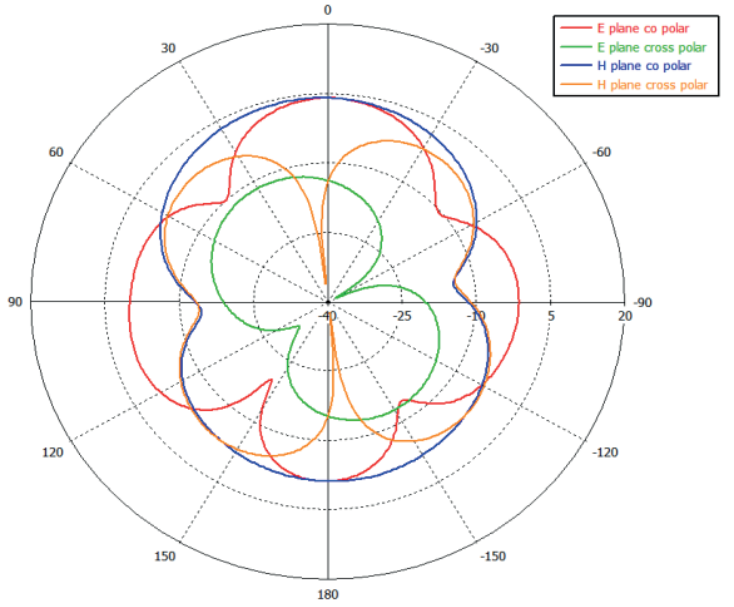

(b)

Fig. 15. Co and cross-polarization radiation patterns in $\mathrm{E}$ and $\mathrm{H}$ planes (a) port 1, (b) port 2.

Table III shows the simulated values of half-power beam width (HPBW) in $\mathrm{E}$ and $\mathrm{H}$ planes.

TABLE III

SIMULATED VALUES OF HPBW

\begin{tabular}{ccc}
\hline \hline Frequency $(\mathrm{GHz})$ & E-Plane & H-Plane \\
\hline 0.538 & $67.8^{\circ}$ & $80.7^{\circ}$ \\
\hline 0.584 & $65.5^{\circ}$ & $86.5^{\circ}$ \\
\hline 0.592 & $65.2^{\circ}$ & $85.8^{\circ}$ \\
\hline \hline
\end{tabular}

Fig. 16 shows the current distributions of the proposed antenna in the RMS value in the frequencies $0.538 \mathrm{GHz}, 0.584$ $\mathrm{GHz}$ and $0.592 \mathrm{GHz}$ in the port 1 and port 2 .

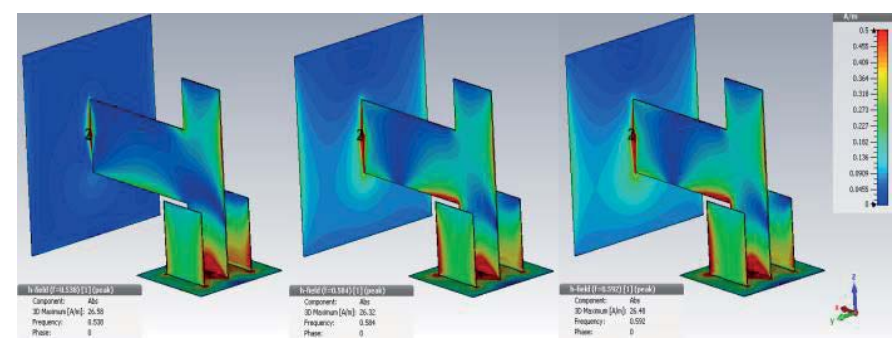

(a)

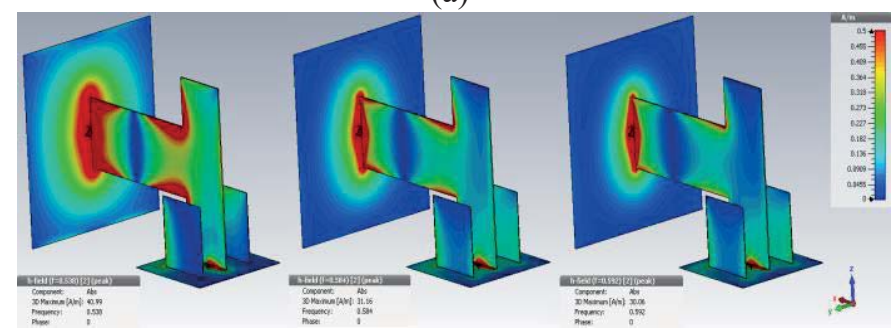

(b)

Fig. 16. Simulated surface current in $\mathrm{dB}$ (RMS) in the frequencies 0.538 $\mathrm{GHz}, 0.584 \mathrm{GHz}$ and $0.592 \mathrm{GHz}$ (a) port 1, (b) port 2 .
Table IV shows the results of the proposed dual-polarized antenna.

TABLE IV

RESULTS OF THE DUAL-POLARIZED ANTENNA

\begin{tabular}{ccc}
\hline \hline Parameters & Port 1 & Port 2 \\
\hline$f_{\text {central }}(\mathrm{GHz})$ & 0.538 & 0.592 \\
\hline S-Parameter $(\mathrm{dB})$ & -29.77 & -15.31 \\
\hline Axial Ratio $(\mathrm{dB})$ & 11 & 9 \\
\hline Gain $(\mathrm{dB})$ & 4.776 & 4.076 \\
\hline Linear Polarization & Vertical & Horizontal \\
\hline \hline
\end{tabular}

\section{CONCLUSION}

In this work, we describe the design and simulations of a dual-polarized antenna for indoor applications. From the simulations developed, we verified that the planar monopole structure presented the best response both in the band criterion and omnidirectionally. Using the technique of addition of parasitic elements in the structure, it was possible to acquire the necessary bandwidth to cover the UHF band. Preliminary results of the simulations were favorable for the modeling of the dual-polarized antenna. A second planar monopole structure was orthogonally attached to the chosen structure, and the results were promising. Through the axial ratio curves, we proved that both structures presented linear polarizations. The Ludwig 3 gain values it was confirmed that the proposed antenna radiates two distinct polarizations. Through of the port 1 , the vertical polarization was obtained and through the port 2 the horizontal polarization. Thus, the results indicate that the proposed antenna satisfy the requirements of bandwidth, HPBW, omnidirectionality, and polarization for being used in the current digital television standard as in the next-generation of digital broadcasting.

\section{ACKNOWLEDGMENT}

The authors would like to express their thanks to Mackenzie Presbyterian University, which provided all the resources for this research, and the technical team from the Digital TV Research Laboratory at Mackenzie Presbyterian University.

\section{REFERENCES}

[1] SET - Sociedade Brasileira de Engenharia de Televisão, "Testes de Interferência do Sinal LTE na Recepção de TV Digital na Faixa de UHF." [Online]. Available: http://set.org.br/tecnologia/SET\%20\%20Resultados\%20dos\%20testes\%20de\%20interfer\%C3\%AAncia_do_ 4G LTE 10.02.2014.pdf.

[2] F. Moura, (2016, Sept), "Testes da SET revelam interferências do 4G na TV Digital." [Online]. Available: http://www.set.org.br/revista-daset/testes-da-set-revelam-interferencias-do-4g-na-tv-digital/.

[3] Y. Wu et al., "Cloud Transmission: A New Spectrum-Reuse Friendly Digital Terrestrial Broadcasting Transmission System". 
In IEEE Transactions on Broadcasting, vol. 58, no. 3, pp. 329337, Sept. 2012

[4] M. M. Bontempo et al., "Desenvolvimento e implementação de uma antena impressa com polarização dupla", in 2016Brazilian Congress of Electromagnetism, Porto Alegre, 2016, pp. 1-6.

[5] K. Woelders and J. Granholm, "Cross-Polarization and Sidelobe Suppression in Dual Linear Polarization Antenna Arrays". In IEEE Transactions on Antennas and Propagation, vol. 45, no. 12, pp. 1727-1740, Dec. 1997.

[6] S. Saito et al., " $8 \mathrm{~K}$ Terrestrial Transmission Field Tests Using Dual-Polarized MIMO and Higher-Order Modulation OFDM". In IEEE Transactions on Broadcasting, vol. 62, no. 1, pp. 306-315, Mar. 2016.

[7] ITU - International Telecommunication Union, "Collection of field trials of UHDTV over DTT networks", Attachment: BT.2343-2, Oct. 2016.

[8] C. A. Balanis, "Antenna Theory: Analysis and Design", $3^{\text {rd }}$ ed., New Jersey of John Wiley and Sons, Inc, 2005, pp. 1117.

[9] M. N. O. Sadiku, "Electromagnetism Elements", $3^{\text {rd }}$ ed., New York of Bookman, 2004, pp. 694.

[10] Z. Berkat and N. B. Hacene, "Design of New Combined Antenna for Dual Polarization Using Crossed Dipole at $2.23 \mathrm{GHz}$ and $5 \mathrm{GHz}$ ", In ARPN Journal of Engineering and Applied Sciences, vol. 10, no. 12, pp. 5164-5168, July, 2015

[11] CST MICROWAVE STUDIO ${ }^{\mathrm{TM}}$. Available: http://www.cst.com, version 2014.

[12] M. J. Ammann and Z. N. Chen, "Wideband monopole antennas for multi-band wireless systems". In IEEE Transactions on Antennas and Propagation, vol. 45, no. 22, pp. 146.150, June, 2003.

[13] M. B. Perotoni, M. V. Stefanelli and E. T. C. dos Santos, "Wideband Planar Monopole Antennas for the Brazilian Digital TV System". In IEEE Latin America Transactions, vol. 13, no. 1, pp. 102-106, Jan, 2015.

[14] E. T. C. dos Santos, "Uma Nova Proposta de Antena Banda Larga para Recepção do Sinal de TV Digital do Padrão ISDB-T,", Thesis (Ph.D. Degree), Mackenzie Presbyterian University, 2016.

[15] N. T. Awano, "Dual Polarized Patch Antenna for UHF RFID Readers", Dissertation (M.Sc. Degree), Tampere University of Technology, 2010.

[16] A. Ludwig, "The definition of cross polarization". In IEEE Transactions on Antennas and Propagation, vol. 21, no. 1, pp. 116-119, Jan, 1973.

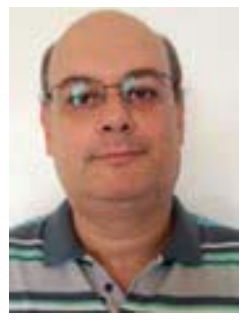

Guilherme Boscolo dos Santos received his B.Sc. degree in Electrical Engineering from Mackenzie Presbyterian University, São Paulo, Brazil, in 2015. He is currently attending towards his Master's degree in Electrical Engineering and Computation at Mackenzie Presbyterian University.

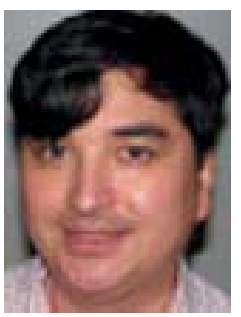

Cristiano Akamine received his B.Sc. degree in Electrical Engineering from Mackenzie Presbyterian University, São Paulo, Brazil, in 1999. He received his M.Sc. and Ph.D. degree in Electrical Engineering from the State University of Campinas (UNICAMP), São Paulo, Brazil, in 2004 and 2011 respectively. He is a professor of Embedded Systems, Software Defined Radio and Advanced Communication Systems at Mackenzie Presbyterian University. He is a researcher in the Digital TV Research Laboratory at Mackenzie Presbyterian University since 1998, where he has had the opportunity to work with many digital TV systems. His research interests are in a system on chip for broadcast TV and Software Defined Radio.

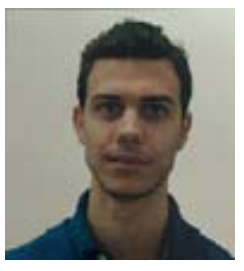

Edson Tafeli Carneiro dos Santos received his B.Sc. degree in Electrical Engineering from Faculty of Industrial Engineering (FEI), São Bernado do Campo, Brazil, in 1993. He received his M.Sc. and Ph.D. degree in Electrical Engineering from Mackenzie Presbyterian University, São Paulo, Brazil, in 2007 and 2016 respectively. He is a professor of Engineering School of Mackenzie Presbyterian University since 1999 and the Faculty of Engineering Mauá since 2012, as well as researcher in the Digital TV Research Laboratory at Mackenzie Presbyterian University. 